УДК 338.28 JEL E69

Глухов Константин Вячеславович ведущий советник, Министерство экономического развития Российской Федерации, г. Москва, Российская Федерация ORCID: 0000-0002-3305-1643 e-mail: konstantinglukhov@gmail.com

Соловьев Иван Александрович студент, ФГБОУ ВО «Российская академия народного хозяйства и государственной службы при Президенте Российской Федерации», г. Москва, Российская Федерация ORCID: 0000-0003-1047-6638 e-mail: solova97@yandex.ru

\section{Glukhov Konstantin}

Lead advicer, Ministry for the Economic Development of Russian Federation, Moscow, Russian Federation ORCID: 0000-0002-3305-1643 e-mail: konstantinglukhov@gmail.com

\section{Solovev Ivan}

Student, Russian Presidential Academy of National Economy and Public Administration, Moscow, Russia ORCID: 0000-0003-1047-6638 e-mail: solova97@yandex.ru
DOI 10.26425/1816-4277-2020-11-83-89

\section{АНТИКРИЗИСНЫЕ РЕШЕНИЯ ДЛЯ РАЗВИТИЯ МАЛОГО И СРЕДНЕГО ПРЕДПРИНИМАТЕЛЬСТВА КАК ФАКТОР ПОВЫШЕНИЯ ЭКОНОМИЧЕСКОЙ БЕЗОПАСНОСТИ ГОСУДАРСТВА}

Аннотация. В статье представлены антикризисные меры поддержки малого и среднего предпринимательства, реализуемье Правительством Российской Федерации в условиях пандемии COVID-19. Также рассмотрен зарубежный опыт использования мер поддержки малого и среднего бизнеса в условиях распространения новой коронавирусной инфекции и были предложены меры по повышению эффективности антикризисных программ по поддержке субъектов малого и среднего предпринимательства в период распространения коронавирусной инфекиии. В данной статье были использованы следующие методы исследования: анализ и обобщение российских и зарубежных антикризисных мер. На основе данного анализа были предложены меры по повышению эффективности антикризисных программ по поддержке субъектов малого и среднего предпринимательства в период распространения коронавирусной инфекции в Российской Федерации.

Ключевые слова: антикризисные меры, зарубежный опыт, кредитные организации, льготное кредитование, малое предпринимательство, Правительство РФ, среднее предпринимательство, субсидирование, COVID-19.

Для цитирования: Глухов К.В., Соловьев И.А. Антикризисные решения для развития малого и среднего предпринимательства как фактор повышения экономической безопасности государства// Вестник университета. 2020. № 11. С. 83-89.

\section{ANTI-CRISIS SOLUTIONS FOR THE DEVELOPMENT OF SMALL AND MEDIUM-SIZED BUSINESSES AS A FACTOR IN IMPROVING THE ECONOMIC SECURITY OF THE STATE}

\begin{abstract}
The article presents anti-crisis measures to support small and medium-sized businesses implemented by the Government of the Russian Federation in the COVID-19 pandemic. The paper reviewed also the foreign experience of using measures to support small and medium-sized businesses in the context of the spread of a new coronavirus infection and proposed measures to improve the effectiveness of anti-crisis programs to support small and medium-sized businesses during the spread of coronavirus infection. The authors used in this article the following research methods: analysis and generalization of Russian and foreign anti-crisis measures. The study proposed, based on this analysis, measures to improve the effectiveness of anti-crisis programs to support small and medium-sized businesses during the spread of coronavirus infection in the Russian Federation.
\end{abstract}

Keywords: anti-crisis measures, COVID-19, credit organizations, foreign experience, Government of the Russian Federation, medium-sized business, preferential lending, small business, subsidization.

For citation: Glukhov K.V., Solovev I.A. (2020) Anti-crisis solutions for the development of small and medium-sized businesses as a factor in improving the economic security of the state. Vestnik universiteta. I. 11, pp. 83-89. DOI: 10.26425/1816-4277-2020-11-83-89

В современных условиях развитие малого и среднего предпринимательства (далее - МСП), а также возможность реализации предпринимательской инициативы граждан являются одним из необходимых условий устойчивого развития страны.

Сегмент МСП играет важную роль как в экономическом, так и в социальном плане, поскольку он позволяет свести к минимуму угрозы экономической безопасности государства.

( С Глухов К.В., Соловьев И.А., 2020. Статья доступна по лицензии Creative Commons «Attribution» («Атрибуция») 4.0. всемирная (http://creativecommons.org/licenses/by/4.0/).

The Author(s), 2020. This is an open access article under the CC BY 4.0 license (http://creativecommons.org/licenses/by/4.0/).

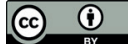


Однако, по большинству показателей в развитии малого и среднего в России наблюдаются отрицательные тенденции. Доля сектора МСП в валовом внутреннем продукте остается крайне низкой в сравнении с зарубежными странами, а также МСП не способствует росту доходов населения, формированию среднего класса и снижению уровня безработицы, то есть не выполняет тех основных социальных функций, которые так важны в обеспечении экономической безопасности государства, и на сегодняшний день, такие угрозы экономической безопасности, как бедность, социальная напряженность и безработица для России остаются актуальными. Пандемия COVID-19 усугубляет и без того печальную ситуацию.

Роль малых предприятий в обеспечении устойчивого экономического развития и решении стоящих перед страной социально-экономических вызовов очевидна, в особенности в период усугубления экономических затруднений, вызванных распространением новой коронавирусной инфекции, поэтому поддержку субъектов МСП стоит рассматривать в качестве одного из приоритетов государственной экономической политики.

В нынешних кризисных условиях необходимо создать тщательно продуманную и научно обоснованную стратегию обеспечения экономической безопасности России в долгосрочной перспективе.

Поэтому одним из главных факторов, определяющих стратегию обеспечения экономической безопасности экономической системы в условиях, наложенных на бизнес вынужденных ограничений, является стабильное и устойчивое развитие малого и среднего бизнеса, что законодательно закреплено во многих станах мира.

В данной статье использовались следующие методы исследования: анализ зарубежного опыта использования мер поддержки малого и среднего бизнеса, а также анализ антикризисных мер Правительства Российской Федерации

Рассмотрим зарубежный опыт использования мер поддержки малого и среднего бизнеса в условиях распространения новой коронавирусной инфекции. Какие меры предпринимаются за рубежом для поддержки малого и среднего бизнеса в условиях введенных ограничений из-за пандемии нового коронавируса.

Китай. Предприятия малого и среднего бизнеса освобождены от уплаты налогов сроком до трех месяцев, а также отложен возврат процентов по кредитам. Снижены требования к кредитным организациям по нормам обязательного резервирования с целью увеличения ликвидности в стране [11].

Япония. Государством разработан механизм льготного кредитования субъектов МСП. Установлены специальные условия кредитования малого и среднего бизнеса: в первые три года процентная ставка снижается на $0,9 \%$ (для организаций, продажи которых сократились более, чем на 5 \%), а также специальная система субсидированных процентных платежей для тех, кто воспользовался особым кредитованием (для малого бизнеса - сокращение продаж более чем на 15 \%, для среднего бизнеса - сокращение продаж более чем на $20 \%$ ). Отсрочка платежа может составлять до пяти лет [9].

Испания. Властями Испании введен шестимесячный мораторий на налоги для малого и среднего бизнеса и самозанятых. Компаниям сокращен на 75 \% взнос на социальное обеспечение. При этом, организации в которых работает менее 50 работников, полностью освобождаются от данного взноса.

Германия. Самозанятые лица и предприниматели с сотрудниками до пяти человек получили экстренную финансовую помощь в совокупном размере до 14 тыс. евро. Для организаций со штатом сотрудников до десяти человек выделили из федерального бюджета до 15 тыс. евро. Кроме того, федеральное Правительство выделило 40 млрд евро для самозанятых и малых фирм (примерно 10 млрд евро), в виде прямых субсидий предприятиям и микропредприятиям, состоящим из одного человека, а 30 млрд евро предоставили в виде льготных кредитов [10].

Великобритания. Среди мер поддержки малого среднего бизнеса правительство Великобритании стоит выделить организацию выплат самозанятым людям, понесшим убытки в условиях пандемии, налогооблагаемого гранта в размере $80 \%$ от их среднемесячной прибыли за последние три года (но не более 2500 фунтов стерлингов в месяц). Таким образом правительство покрывает ту же сумму дохода для работающего не по найму человека, как и для уволенных сотрудников, которые также получают грант в размере 80 \%. При этом указанные гранты облагаются налогом, который должен быть внесен в налоговую декларацию до января 2022 г. [12].

Рассмотрим теперь антикризисные меры, предпринятые Правительством Российской Федерации. Развитие малого и среднего бизнеса является фактором, который способствует повышению экономической безопасности страны. Можно предложить ряд антикризисных мер, которые будут способствовать реализации данной очень важной социально-экономической задачи. 
Особое внимание следует уделить устойчивому развитию МСП, которое сегодня имеет решающее значение в решении сложных социально-экономических проблем, возникающих в условиях мирового экономического кризиса. Данная устойчивость дополняется вовлечением в предпринимательский сектор значительной части безработных, переподготовкой денежной и бюджетной политики, а также стимулированием развития реального сектора экономики. Доступ к финансовым ресурсам является одним из основополагающих факторов «выживания» малого и среднего бизнеса в период введения ограничительных мер [8].

В 2020 г. льготные кредиты МСП предоставляются в рамках реализации Правил предоставления субсидий из федерального бюджета российским кредитным организациям и специализированным финансовым обществам на возмещение недополученных ими доходов по кредитам, выданным в 2019-2024 гг. субъектам МСП, а также физическим лицам, применяющим специальный налоговый режим «Налог на профессиональный доход», по льготной ставке, утвержденных Постановлением Правительства Российской Федерации от 30 декабря 2018 г. № 1764 (далее - Правила 1764) [4].

Конечная ставка по кредитному договору на инвестиционные цели, кредитному договору на пополнение оборотных средств и кредитному договору на рефинансирование, предоставляемым уполномоченными банками по Правилам 1764, составляет не более 8,5 \% годовых и не более 9,95 \% годовых по кредитному договору на развитие предпринимательской деятельности.

В соответствии с пунктом 4 Правил 1764 уполномоченный банк вправе предоставить заемщику, осуществляющему деятельность в одной или нескольких приоритетных отраслях (видах деятельности), предусмотренных Правилами 1764, льготный кредит на пополнение оборотных средств в размере от 500 тыс. рублей до 500 млн рублей на срок до трех лет, от 5 тыс. рублей до 2 млрд рублей на срок до десяти лет - на инвестиционные цели.

Для участия в реализации Правил 1764 Министерством экономического развития Российской Федерации отобрано более 90 уполномоченных банков, включая крупнейшие российские банки с развитой филиальной сетью, а также некрупные региональные банки, которые имеют опыт кредитования малого и среднего бизнеса.

Заемщик по Правилам 1764 вправе обратиться в любую из кредитных организаций, участвующих в программе в целях получения льготного кредита. При этом кредитная организация принимает решение о предоставления кредита в том числе в соответствии с правилами и процедурами, принятыми в данной кредитной организации.

В связи с неблагоприятной эпидемиологической обстановкой на территории Российской Федерации выработан План первоочередных мероприятий (действий) по обеспечению устойчивого развития экономики в условиях ухудшения ситуации в связи с распространением новой коронавирусной инфекции (далее - План) [7].

Для реализации Плана принято Постановление Правительства Российской Федерации от 31 марта 2020 г. № 372 «О внесении изменений в Правила предоставления субсидий из федерального бюджета российским кредитным организациям и специализированным финансовым обществам на возмещение недополученных ими доходов по кредитам, выданным в 2019-2024 годах субъектам МСП, а также физическим лицам, применяющим специальный налоговый режим «Налог на профессиональный доход», по льготной ставке» (далее - Постановление 372) [5].

Постановление 372 предусматривает оптимизацию параметров Правил 1764 в части:

- упрощения требования к заемщику (исключено требование об отсутствии задолженности по налогам, сборам, об отсутствии задолженности по заработной плате, об отсутствии просроченных на срок свыше 30 календарных дней платежей по кредитным договорам (соглашениям));

- отмены ограничения по максимально возможному объему кредитных договоров (соглашений) на рефинансирование;

- разрешено рефинансирование кредитных договоров (соглашений) на оборотные цели;

- расширена возможность получения кредитов по льготной ставке для микропредприятий в сфере торговли за счет включения возможности реализации подакцизных товаров.

В соответствии с Планом также принято постановление Правительства Российской Федерации от 2 апреля 2020 г. № 410 «Об утверждении Правил предоставления в 2020 году субсидий из федерального бюджета российским кредитным организациям на обеспечение отсрочки платежа по кредитам, выданным субъектам малого и среднего предпринимательства» (далее - Правила 410) [1].

В соответствии с Правилами 410 субсидии предоставляются российским кредитным организациям в целях компенсации понесенных затрат получателей субсидии в связи с освобождением заемщика от платежей 
по начисленным процентам по кредитным договорам (соглашениям) на период не более шести месяцев (не ранее 1 апреля 2020 г. и не позднее 31 декабря 2020 г.). Срок предоставления права отсрочки платежа должен составлять шесть месяцев. При предоставлении заемщику права отсрочки платежа процентная ставка по кредитному соглашению не увеличивается. Заемщик, соответствующий требованиям, установленным пунктом 7 Правил 410, вправе обратиться в уполномоченный банк в целях получения отсрочки платежа по кредиту.

Также в рамках антикризисных мер принято постановление Правительства Российской Федерации от 2 апреля № 422 «Об утверждении Правил предоставления субсидий из федерального бюджета российским кредитным организациям на возмещение недополученных ими доходов по кредитам, выданным в 2020 г. юридическим лицам и индивидуальным предпринимателям на неотложные нужды для поддержки и сохранения занятости» (далее - Правила 422) [2].

В соответствии с Правилами 422 на выплату заработной платы субсидии предоставляются российским банкам, участвующим в Программе в целях возмещения недополученных ими доходов по кредитам, выданным в 2020 г. юридическим лицам и индивидуальным предпринимателям на выплату заработной платы работникам по ставке для заемщика 0 \%. Заемщик, соответствующий требованиям, установленным пунктом 7 Правил 422, вправе обратиться в уполномоченный банк в целях получения кредита по нулевой ставке.

Кроме того, в рамках антикризисных мер принято постановление Правительства Российской Федерации от 16 мая № 696 «Об утверждении Правил предоставления субсидий из федерального бюджета российским кредитным организациям на возмещение недополученных ими доходов по кредитам, выданным в 2020 г. юридическим лицам и индивидуальным предпринимателям на возобновление деятельности» (далее - Постановление 696) [3].

В соответствии с Постановлением 696 субсидии предоставляются российским банкам, участвующим в Программе в целях возмещения недополученных ими доходов по кредитам, выданным в 2020 г. юридическим лицам и индивидуальным предпринимателям на возобновление деятельности по ставке для заемщика не выше $2 \%$.

У заемщика, сохранившего списочную численность сотрудников не менее 90 \% к марту 2021 г., списывается кредитная задолженность по Постановлению 696 в полном объеме. При сохранении списочной численности сотрудников не менее 80 \% - списывается половина кредитной задолженности по Постановлению 696.

Перечень отраслей российской экономики, в наибольшей степени пострадавших в условиях ухудшения ситуации в результате распространения новой коронавирусной инфекции утвержден Постановлением Правительства Российской Федерации от 3 апреля 2020 г. № 434 [6]. Следует отметить, что в случае, если в данном перечне приведен целиком класс или подкласс все входящие в него группировки (группы, подгруппы, виды) также в него включены.

Реализуемые меры не лишены ряда недостатков, наиболее значимыми из которых являются следующие:

- не все виды деятельности включены в перечень пострадавших отраслей, равно как и не все субъекты МСП могут претендовать на получение помощи от государства по ряду программ (например, индивидуальные предприниматели, не имеющие наемных работников);

- помощь зачастую оказывается опосредованно, через кредитные организации, которым государство компенсирует ставку по ряду льготных кредитов. Это приводит к тому, что ряд индивидуальных предпринимателей и юридических лиц - субъектов МСП получают отказы в банках в получении льготных кредитов по антикризисным программам без объяснения причин;

- выделяемых средств и размеров льготных кредитов не всегда достаточно чтобы компенсировать полученные потери и предотвратить банкротство субъекта МСП.

Рассмотрим предлагаемые меры по повышению эффективности антикризисных программ по поддержке субъектов МСП в период распространения коронавирусной инфекции.

По результатам анализа российских и зарубежных мер поддержки субъектов МСП в условиях распространения коронавирусной инфекции можно сделать вывод, что меры, применяемые за рубежом, являются достаточно разнообразными. Так, в азиатских странах, таких как Китай, Япония, Республика Корея сделан упор на механизм льготного кредитования субъектов МСП, а также на освобождение малого и среднего бизнеса от кредитных обязательства, в то время как в странах Европейского союза сделан упор на освобождение субъектов МСП от налоговых обязательств, а также на финансовую помощь и субсидии. В России также реализуется как механизм льготного кредитования субъектов МСП, так и субсидирование, однако данные меры имеют определенные недостатки и нуждаются в доработке. 
Реализуемые меры поддержки МСП важны, но недостаточны. Размер финансовой помощи, предоставленный субъектам МСП невелик, он позволяет только не обанкротиться, но не дает ресурсов для развития. Так, из бюджета Российской Федерации на помощь малому бизнесу выделили 10 \% бюджета, зарезервированного на период кризисных ситуаций. При этом, например, в США, выделяется более 50 \% бюджета для малого и среднего бизнеса, предназначенного на чрезвычайный случай.

Поэтому, среди прочих мер по поддержке малого и среднего бизнеса, исходя из анализа поднимающихся в обращениях граждан в органы исполнительной власти, необходимо реализовать следующие меры:

- распространение антикризисных мер (программ) на самозанятых, включение их в перечень имеющих право на получение компенсации/льготного кредита;

- распространение антикризисных мер на индивидуальных предпринимателей, состоящие из одного человека (без наемных работников);

- расширение перечня пострадавших отраслей, распространение мер поддержки на все субъекты малого и среднего предпринимательства;

- максимально освободить малый и средний бизнес от всех кредитных и налоговых обязательств, предотвратив их банкротство и сохранив рабочие места;

- введение поддержки для малого и среднего бизнеса, заключившего договора аренды.

\section{Библиографический список}

1. Постановление Правительства РФ от 02.04.2020 № 410 (ред. от 24.04.2020) «Об утверждении Правил предоставления в 2020 году субсидий из федерального бюджета российским кредитным организациям на обеспечение отсрочки платежа по кредитам, выданным субъектам малого и среднего предпринимательства» // СПС «КонсультантПлюс» [Электронный pecypc]. - Режим доступа: http://www.consultant.ru/document/cons_doc_LAW_349388/ (дата обращения: 18.08.2020).

2. Постановление Правительства РФ от 02.04.2020 № 422 (ред. от 24.04.2020) «Об утверждении Правил предоставления субсидий из федерального бюджета российским кредитным организациям на возмещение недополученных ими доходов по кредитам, выданным в 2020 году юридическим лицам и индивидуальным предпринимателям на неотложные нужды для поддержки и сохранения занятости» // СПС «КонсультантПлюс» [Электронный ресурс]. - Режим доступа: http:// www.consultant.ru/document/cons_doc_LAW_349384/(дата обращения: 18.08.2020).

3. Постановление Правительства РФ от 16.05.2020 г. № 696 (ред. от 11.07.2020) «Об утверждении Правил предоставления субсидий из федерального бюджета российским кредитным организациям на возмещение недополученных ими доходов по кредитам, выданным в 2020 году юридическим лицам и индивидуальным предпринимателям на возобновление деятельности» // СПС «КонсультантПлюс» [Электронный ресурс]. - Режим доступа: http://www.consultant.ru/document/ cons_doc_LAW_352711/(дата обращения: 18.08.2020).

4. Постановление Правительства РФ от 30.12.2018 г. № 1764 «Об утверждении Правил предоставления субсидий из федерального бюджета российским кредитным организациям на возмещение недополученных ими доходов по кредитам, выданным в 20192024 годах субъектам малого и среднего предпринимательства по льготной ставке» // Официальный сайт Правительства Российской Федерации [Электронный ресурс]. - Режим доступа: http://government.ru/docs/all/120116/ (дата обращения: 18.08.2020).

5. Постановление Правительства Российской Федерации от 31.03 .2020 № 372 «О внесении изменений в Правила предоставления субсидий из федерального бюджета российским кредитным организациям и специализированным финансовым обществам на возмещение недополученных ими доходов по кредитам, выданным в 2019-2024 годах субъектам малого и среднего предпринимательства, а также физическим лицам, применяющим специальный налоговый режим «Налог на профессиональный доход», по льготной ставке» // СПС «КонсультантПлюс» [Электронный ресурс]. - Режим доступа: http://www.consultant.ru/document/cons_doc_LAW_349088/(дата обращения: 18.08.2020).

6. Постановление Правительства РФ от 03.04.2020 № 434 «Об утверждении перечня отраслей российской экономики, в наибольшей степени пострадавших в условиях ухудшения ситуации в результате распространения новой коронавирусной инфекции» // СПС «КонсультантПлюс» [Электронный ресурс]. - Режим доступа: http://www.consultant.ru/document/ cons_doc_LAW_349344/(дата обращения: 18.08.2020).

7. План первоочередных мероприятий (действий) по обеспечению устойчивого развития экономики в условиях ухудшения ситуации в связи с распространением новой коронавирусной инфекции (утвержденный Правительством Российской Федерации 17.03.2020, № 2182p-P13) // СПС «КонсультантПлюс» [Электронный ресурс]. - Режим доступа: http://www. consultant.ru/document/cons_doc_LAW_348153/ (дата обращения: 18.08.2020). 
8. Буров, В. Ю. Малое предпринимательство в системе обеспечения экономической безопасности // Известия Байкальского государственного университета. - 2014. - Т. 97. - № 5. - С. 101-107.

9. Заболоцкая, В. В., Хут, Н. А. Сравнительный анализ мер государственной поддержки малого и среднего бизнеса // Теория и практика общественного развития. - 2015. - Т. 10. - № 11. - С. 46-49.

10. Луцкая, Е. Е. Стратегия преодоления кризиса COVID 19 в США и ЕC // Социальные и гуманитарные науки: Отечественная и зарубежная литература. Сер. 2, Экономика: Реферативный журнал. - 2020. - Т. 4. - № 11. - С. 44-50.

11. Передера, Ж. С., Гриценко, Т. С., Правиков, О. В. Развитие системы кредитования малого и среднего бизнеса в России на основе зарубежного опыта // Московский экономический журнал. - 2019. - № 1. - С. 230-242.

12. Симэн, Е., Шершешева, М. Ю. Государственная политика КНР в отношении китайских малых и средних предприятий в условиях COVID 19 // Государственное управление. Электронный вестник - 2020. - № 79. - С. 25-49.

\section{References}

1. Postanovlenie Pravitel'stva RF ot 02.04.2020 № 410 (red. ot 24.04.2020) “Ob utverzhdenii Pravil predostavleniya v 2020 godu subsidii iz federal'nogo byudzheta rossiiskim kreditnym organizatsiyam na obespechenie otsrochki platezha po kreditam, vydannym sub"ektam malogo i srednego predprinimatel'stva" [Resolution of the Government of the Russian Federation "On Aapproval of the Rules for Granting Subsidies from the Federal Budget to Russian Credit Organizations in 2020 to Ensure Deferred Payment on Loans Issued to Small and Medium-Sized Businesses" No. 410, dated on April 2, 2020 (as amended, dated on April 24, 2020)]. Legal reference system “ConsultantPlus". Available at: http://www.consultant.ru/document/cons_doc_LAW_349388/ (accessed 18.08.2020).

2. Postanovlenie Pravitel’stva RF ot 02.04.2020 № 422 (red. ot 24.04.2020) “Ob utverzhdenii Pravil predostavleniya subsidii iz federal'nogo byudzheta rossiiskim kreditnym organizatsiyam na vozmeshchenie nedopoluchennykh imi dokhodov po kreditam, vydannym v 2020 godu yuridicheskim litsam i individual'nym predprinimatelyam na neotlozhnye nuzhdy dlya podderzhki i sokhraneniya zanyatosti" [Resolution of the Government of the Russian Federation "On Approval of the Rules for Granting Subsidies from the Federal Budget to Russian Credit organizations for Compensation of Lost Income on Loans Issued in 2020 to Legal Entities and Individual Entrepreneurs for Urgent Needs to Support and Maintain Employment" No. 422, dated on April 2, 2020 (as amended, dated on April 24, 2020)]. Legal reference system "ConsultantPlus". Available at: http://www.consultant. ru/document/cons_doc_LAW_349384/(accessed 18.08.2020).

3. Postanovlenie Pravitel’stva RF ot 16 maya 2020 g. № 696 (red. ot 11.07.2020) “Ob utverzhdenii Pravil predostavleniya subsidii iz federal'nogo byudzheta rossiiskim kreditnym organizatsiyam na vozmeshchenie nedopoluchennykh imi dokhodov po kreditam, vydannym v 2020 godu yuridicheskim litsam i individual'nym predprinimatelyam na vozobnovlenie deyatel'nosti” [Resolution of the Government of the Russian Federation "On Approval of the Rules for Granting Subsidies from the Federal Budget to Russian Credit Organizations for Compensation of Lost Income on Loans Issued in 2020 to Legal Entities and Individual Entrepreneurs for the Resumption of Activity» № 696, dated on May 16, 2020 (as amended, dated on July 11, 2020)]. Legal reference system "ConsultantPlus". Available at: http://www.consultant.ru/document/cons_doc_LAW_352711/(accessed 18.08.2020).

4. Postanovlenie Pravitel’stva RF ot 30 dekabrya 2018 g. № 1764 “'Ob utverzhdenii Pravil predostavleniya subsidii iz federal'nogo byudzheta rossiiskim kreditnym organizatsiyam na vozmeshchenie nedopoluchennykh imi dokhodov po kreditam, vydannym v 2019-2024 godakh sub"ektam malogo i srednego predprinimatel'stva po l'gotnoi stavke" [Resolution of the Government of the Russian Federation "On Approval of the Rules for Granting Subsidies from the Federal Budget to Russian Credit Organizations for Reimbursement of Lost Income on Loans Issued in 2019-2024 to Small and Medium-Sized Businesses at a Preferential Rate" № 1764, dated on December 30, 2018]. Ofitsial ’nyi sait Pravitel'stva Rossiiskoi Federatsii [Official website of the Government of the Russian Federation]. Available at: http://government.ru/docs/all/120116/ (accessed 18.08.2020).

5. Postanovlenie Pravitel’stva Rossiiskoi Federatsii ot 31 marta 2020 g. № 372 “O vnesenii izmenenii v Pravila predostavleniya subsidii iz federal'nogo byudzheta rossiiskim kreditnym organizatsiyam i spetsializirovannym finansovym obshchestvam na vozmeshchenie nedopoluchennykh imi dokhodov po kreditam, vydannym v 2019-2024 godakh sub"ektam malogo i srednego predprinimatel'stva, a takzhe fizicheskim litsam, primenyayushchim spetsial'nyi nalogovyi rezhim "Nalog na professional'nyi dokhod", po l'gotnoi stavke" [Resolution of the Government of the Russian Federation "On Amendments to the Rules for Granting Subsidies from the Federal Budget to Russian Credit Organizations and Specialized Financial Companies for Reimbursement of Lost Income on Loans Issued in 2019-2024 to Small and Medium-Sized Businesses, as well as Individuals Applying the Special Tax Regime "Professional Income Tax" at a Preferential Rate", No. 372, dated on March 31, 2020]. Legal reference system "ConsultantPlus". Available at: http://www.consultant.ru/document/cons_doc_LAW_349088/(accessed 18.08.2020). 
6. Postanovlenie Pravitel’stva RF ot 3 aprelya 2020 g. № 434 “'Ob utverzhdenii perechnya otraslei rossiiskoi ekonomiki, v naibol’shei stepeni postradavshikh v usloviyakh ukhudsheniya situatsii v rezul'tate rasprostraneniya novoi koronavirusnoi infektsii” [Resolution of the Government of the Russian Federation "On Approval of the List of Sectors of the Russian Economy, the Worst Affected in the Deteriorating Situation with the Spread of a New Coronavirus Infection” № 434, dated on April 3, 2020]. Legal reference system "ConsultantPlus". Available at: http://www.consultant.ru/document/cons_doc_LAW_349344/(accessed 18.08.2020).

7. Plan pervoocherednykh meropriyatii (deistvii) po obespecheniyu ustoichivogo razvitiya ekonomiki v usloviyakh ukhudsheniya situatsii v svyazi s rasprostraneniem novoi koronavirusnoi infektsii (utverzhdennyi Pravitel'stvom Rossiiskoi Federatsii 17.03.2020 № 2182r-R13) [Plan of priority measures (actions) to ensure sustainable economic development in the context of the deterioration of the situation due to the spread of a new coronavirus infection (approved by the Government of the Russian Federation No. 2182r-R13, dated on March 17, 2020)]. Legal reference system “ConsultantPlus". Available at: http://www. consultant.ru/document/cons_doc_LAW_348153/(accessed 18.08.2020).

8. Burov V.Yu. Maloe predprinimatel'stvo v sisteme obespecheniya ekonomicheskoi bezopasnosti [Small business in the system of ensuring economic security]. Izvestiya Baikal'skogo gosudarstvennogo universiteta [Bulletin of Baikal State University], 2014, no. 5, pp. 101-107.

9. Zabolotskaya V. V., Khut N.A. Sravnitel'nyi analiz mer gosudarstvennoi podderzhki malogo i srednego biznesa [Comparative analysis of state support measures for small and medium-sized businesses]. Teoriya i praktika obshchestvennogo razvitiya [Theory and Practice of Social Development], 2015, no.11, pp. 46-49.

10. Lutskaya E.E. Strategiya preodoleniya krizisa COVID $19 \mathrm{v}$ SShA i ES [The strategy to overcome the COVID 19 crisis in the $U S$ and $E U]$. Sotsial'nye i gumanitarnye nauki: Otechestvennaya i zarubezhnaya literatura. Ser. 2, Ekonomika: Referativnyi zhurnal, 2020, no.11, pp. 44-50.

11. Peredera Zh.S., Gritsenko T.S., Pravikov O.V. Razvitie sistemy kreditovaniya malogo i srednego biznesa v Rossii na osnove zarubezhnogo opyta [Development of the small and medium-sized business lending system in Russia based on foreign experience]. Moskovskii ekonomicheskii zhurnal [Moscow journal], 2019, no.1 pp. 230-242.

12. Simen E. Shershesheva M.Yu. Gosudarstvennaya politika KNR v otnoshenii kitaiskikh malykh i srednikh predpriyatii v usloviyakh COVID 19 [State policy of Republic of China on Chinese small and medium-sized enterprises in the context of COVID 19]. Gosudarstvennoe upravlenie. Elektronnyi vestnik [Public Administration. E-Journal], 2020, no.79, pp. 25-49. 